\title{
Colour polymorphism in Drosophila mediopunctata: genetic (chromosomal) analysis and nonrandom association with chromosome inversions
}

\author{
LM Hatadani ${ }^{1}$, JCR Baptista ${ }^{2}$, WN Souza ${ }^{1}$ and LB Klaczko ${ }^{1}$ \\ ${ }^{1}$ Departamento de Genética e Evolução, Instituto de Biologia, Universidade Estadual de Campinas (UNICAMP), Cx. Postal 6109, \\ Campinas, 13083-970 SP, Brazil; '2Departamento de Genética, Instituto de Biologia, Universidade Federal do Rio de Janeiro (UFRJ), \\ Rio de Janeiro, 21949-900 RJ, Brazil
}

The presence of three dark spots on the abdomen is typical of the tripunctata group of Drosophila, which is the second largest Neotropical group, with 56 species. In some species, such as $D$. mediopunctata, the colour pattern varies considerably: ranging from flies showing no spots up to flies with three dark spots. In this paper, we present a genetic (chromosomal) analysis of this character showing that this colour polymorphism is genetically determined mainly by the second chromosome. Since this chromosome is the most polymorphic for inversions in this species, we also examined the influence of the inversions on this character. We used strains in which different second chromosomes were placed on the same genetic background and the offspring between them. We found a nonrandom association between the number of spots and the inversions $P A O$ and $P C O$. Thus, our results are consistent with the idea that the factors or genes determining a conspicuous polymorphism are likely to be associated, forming a supergene, and this association would be most efficiently accomplished through a chromosome inversion. Moreover, this is the first time that an association between a conspicuous morphological polymorphism and chromosome inversions has been described.

Heredity (2004) 93, 525-534. doi:10.1038/sj.hdy.6800544

Published online 11 August 2004

Keywords: pigmentation; supergene; colour polymorphism; tripunctata; gene arrangement; conspicuous polymorphism

\section{Introduction}

The adaptive nature of chromosome inversions in Drosophila has been accepted since Dobzhansky's classic work (Wright and Dobzhansky, 1946), which first established that different chromosomal arrangements were under natural selection.

As no recombinants are produced between genes within different inversions - crossingover is suppressed within the inverted region in inversion heterozygotes Dobzhansky (1970) believed that inversions could be considered supergenes, which accumulated coadapted alleles. Ford (1964) thought that including coadapted alleles in a chromosome inversion was the most effective way to ensure that they would segregate as a block, to produce only high fitness phenotypic variants. Ford also proposed that polymorphic adaptations occurred mainly through a genetic architecture in which genes are tightly linked so that they act as a single unit. Inversion polymorphisms in Drosophila have been associated with several fitness-related characters (Rodríguez et al, 1999), behaviour (Dahlgaard et al, 2001) and morphological traits (Izquierdo et al, 1991; Bitner-Mathé et al, 1995; Bertrán et al, 1998). Recently there has been a resurgence of interest in the significance of chromosomal inversions in evolution

Correspondence: LB Klaczko, Departamento de Genética e Evolução, Instituto de Biologia, UNICAMP, Cx. Postal 6109, Campinas, 13083-970 SP, Brazil.E-mail: LBK@unicamp.br

Received 14 April 2004; accepted 28 May 2004; published online 11 August 2004 and speciation. Noor et al (2001) studied the genetic basis of hybrid sterility between Drosophila pseudoobscura and $D$. persimilis. They concluded that inversions could create linkage groups that cause sterility between hybridising taxa which would favour reproductive isolation. It has also been proposed that the reduction in recombination caused by chromosome inversions could act synergistically with isolation genes and increase the plausibility of certain models of speciation (Rieseberg, 2001).

There are presently about 2000 known species of Drosophila (Powell, 1997). Yet, only a few cases of colour polymorphism have been examined in this genus. One of the best studied cases is D. polymorpha. da Cunha (1949) identified one locus and two alleles (with no dominance) that determined the abdomen colour pattern polymorphism in this species. Heed and Blake (1963) later found another allele, and Martinez and Cordeiro (1970) discovered that modifiers segregated independently of the major locus. In D. kikkawai, abdominal colour polymorphism is determined by one locus and two alleles (Gibert et al, 1999), whereas in D. lebanonensis, the colour of the thorax is controlled by one locus (two alleles) and modifiers (Pipkin, 1962).

The tripunctata group is the second largest Neotropical group of Drosophila in number of species, with 56 described species (Vilela, 1992). It is particularly abundant in forested areas of southern Brazil during the winter (Saavedra et al, 1995). The group name tripunctata is derived from the presence of three dark spots on the last tergites of the abdomen. However, not all species show this trait. In some species, there is only a dark band 
on the last tergite instead of three spots, while in others there is intraspecific variation (Frota-Pessoa, 1954). This is the case in D. mediopunctata, a species distributed from southern South America to Central America. The abdominal colour pattern in D. mediopunctata varies considerably, from no spots to three dark spots, on the fourth, fifth and sixth abdominal tergites. In addition to number, these spots also vary in size. Males tend to have more and bigger spots than females (Frota-Pessoa, 1954).

$D$. mediopunctata has six pairs of chromosomes: five acrocentrics and a dot that does not undergo polytenisation. The $X$, second and fourth chromosomes are polymorphic for inversions. The second chromosome is the most polymorphic and its inversions can be divided into two groups according to the region as follows: there are eight inversions in the distal region $(D A, D P, D S, D V$, etc) and nine in the proximal region $(P A 0, P B 0, P C 0, P C 1$, etc) (Ananina et al, 2002). There is intense linkage disequilibrium between distal and proximal inversions, for example, $D A$ is associated with $P A 0$, with a $D^{\prime}$ value of $0.98 ; D P$ is associated with $P C 0\left(D^{\prime}=0.97\right)$; and $D S$ with PCO $\left(D^{\prime}=0.95\right)$ (Peixoto and Klaczko, 1991).

In this paper, we present a genetic (chromosomal) analysis of the variation of the number of abdominal spots in D. mediopunctata. We show that this colour polymorphism is genetically determined mainly by one chromosome (the second chromosome). Examination of the influence of inversions of this chromosome on the character reveals a nonrandom association between inversions $P A O$ and $P C O$ and the number of spots. To our knowledge, this is the first time a conspicuous morphological polymorphism has been found to be associated with chromosome inversions.

\section{Materials and methods}

\section{The colour polymorphism}

The number of spots was counted on flies that were at least 4 days old, by which time the colour intensity had stabilised. The number of spots varied, with flies possessing no spots, one (on the sixth tergite), two spots (on the fifth and sixth tergites) and three spots (on the fourth, fifth and sixth tergites) (Frota-Pessoa, 1954). In flies with three spots, the spot on the fourth tergite sometimes merges with the posterior pigmented band. In these cases, the phenotype was scored as ' $3 \mathrm{D}$ ', but the entire analysis was carried out by considering this pattern as having three spots.

\section{Strains used in the genetic analysis}

The following strains were used:

- ITC-29I: A strain selected for zero spots and brothersister crossed for over 20 generations.

- NA: A marker strain (Carvalho and Klaczko, 1993) carrying the visible mutations $\Delta$ (Delta), Im (Impar), cr (coral) and al (alfinete) on the second, third, fourth and fifth chromosomes, respectively, and sharing its $\mathrm{X}$ and $Y$ chromosomes with strain CR27A.

- CR27A: A marker strain carrying the dominant visible mutations $\Delta-5$ (Delta-5) on the second chromosome, and the recessive mutations $c b$ (cabernet), $c r$ (coral) and al (alfinete) on the third, fourth and fifth chromosomes, respectively. This strain shares its $\mathrm{X}$ and $\mathrm{Y}$ chromosomes with strain CR27B.
- CR27B: A marker strain carrying the visible mutations $c b$ (cabernet), cr (coral) and al (alfinete) on the third, fourth and fifth chromosomes, respectively, and sharing its $\mathrm{X}$ and $\mathrm{Y}$ chromosomes with strain CR27A.

In strain ITC-29I, the zero spot phenotype was fixed whereas in the remaining strains the three spots phenotype was fixed.

\section{Marker strains used to produce strains with the same genetic background \\ The following strains were used:}

- CR26A: A marker strain carrying the recessive mutations $m t$ (merlot), $\mathrm{cr}$ (coral) and al (alfinete) on the second, fourth and fifth chromosomes, respectively. This strain shares its $\mathrm{X}$ and $\mathrm{Y}$ chromosomes with strains CR26B, CR26C and CR26J. The second chromosome karyotype is $D V-P C 0 / D V-P C 0$.

- CR26B: A marker strain carrying the dominant visible mutation $\Delta$ (Delta) on the second chromosome, and the recessive mutations $m t$ (merlot), $\mathrm{cr}$ (coral) and al (alfinete) on the second, fourth and fifth chromosomes. The second chromosome karyotype is $D V-P C O / D V$ PCO.

- CR26C: A marker strain carrying the dominant visible mutation Im (Impar) on the third chromosome, and the recessive mutations $m t$ (merlot), $\mathrm{cr}$ (coral) and al (alfinete) on the second, fourth and fifth chromosomes, respectively. The second chromosome karyotype is $D V-P C 0 / D V-P C 0$.

- CR26J: A marker strain carrying the dominant visible mutation $\Delta-5$ (Delta-5) on the second chromosome, and the recessive mutations $m t$ (merlot), $\mathrm{cr}$ (coral) and al (alfinete) on the second, fourth and fifth chromosomes, respectively. The second chromosome karyotype is $D A-P A 0 / D V-P C 0$.

Strains CR26A, CR26B, CR26C and CR26J share their sex chromosomes.

\section{Strains with different second chromosomes on the same} genetic background

To test whether there was a nonrandom association between second chromosome inversions and the phenotypes of dark abdominal spots, we produced strains that differed from each other on the second chromosome but shared the same genetic background. We used isofemale lines obtained from two collections made in Serra do Japi, SP, Brazil $\left(23^{\circ} 11^{\prime} S, 46^{\circ} 40^{\prime} \mathrm{W}\right)$ in July 1994 and May 1995. The females were crossed with marker strains (CR26A, CR26B, CR26C and CR26J) and the second chromosome was then made autozygous by inbreeding (Figure 1).

Females from the isofemale line were initially crossed with males from strain CR26C (Figure 1). From the offspring, we selected males with phenotype Impar, which were heterozygous for the recessive markers $m t$, $\mathrm{cr}$ and $\mathrm{al}$, and for the dominant marker $\mathrm{Im}$. These males were individually crossed with females from strain CR26A and males with the phenotypes Impar, coral and alfinete were selected from the offspring. Thus, the fourth and fifth chromosomes from the isofemale line were replaced by the corresponding marked chromosomes. The selected males were crossed with females 


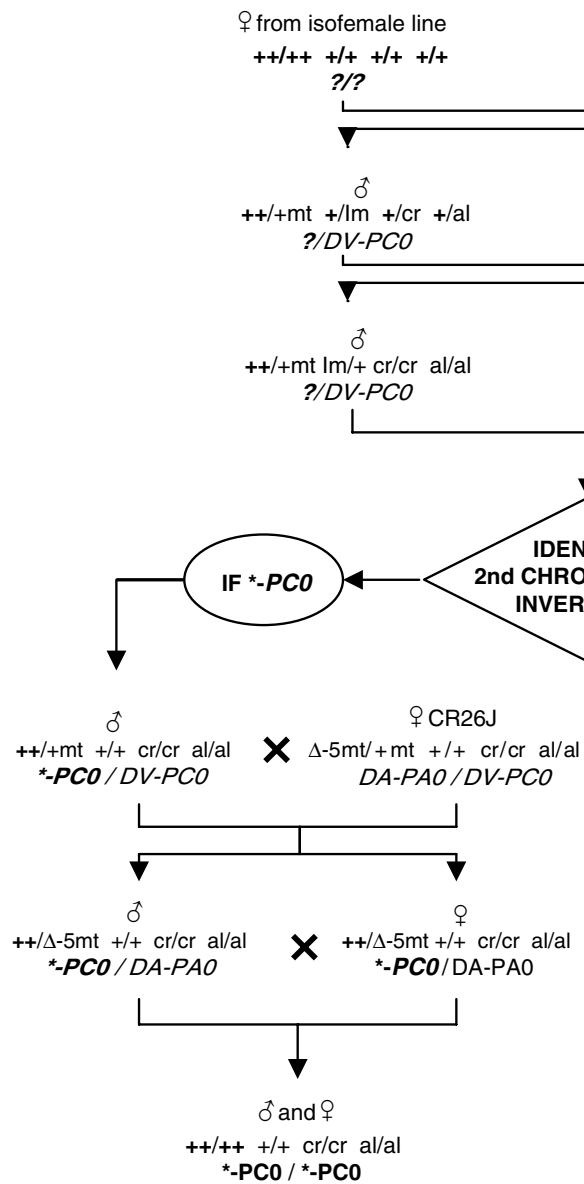

$X \quad O C R 26 C$

$+\mathrm{mt} /+\mathrm{mt} \mathrm{Im} /+\mathrm{cr} / \mathrm{cr}$ al/al

DV-PCO / DV-PCO

$x$

+CR26A

$+\mathrm{mt} /+\mathrm{mt}+/+\mathrm{cr} / \mathrm{cr}$ al/al $D V-P C O / D V-P C O$

$+\mathrm{mt} /+\mathrm{mt}+/+\mathrm{cr} / \mathrm{cr}$ al/al $D V-P C O / D V-P C O$

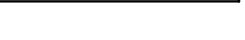

\section{.}


is fixed to phenotype 3 and has a recessive lethal mutation with a dominant visible effect (Delta-5, $\Delta-5$ ), heterozygous on the second chromosome. The strain is homozygous for recessive mutations on the third, fourth and fifth chromosomes. Male offspring with phenotype $\Delta$ were backcrossed with strain CR27B. This strain carries the same mutations on the third, fourth and fifth chromosomes as CR27A, but is homozygous for the wild allele of $\Delta-5$. The offspring were raised under controlled conditions of temperature $\left(16.5^{\circ} \mathrm{C}\right)$ and density (20 larvae/vial). Since there is no crossingover in males of D. mediopunctata, it is possible to assess the influence of each of the marked chromosomes. If the distribution of phenotypes is independent of the genotype of the markers, then there is no influence of the chromosome; otherwise, the chromosome carries at least one factor that determines the character.

\section{Strains carrying different inversions on the same background}

First instar larvae were collected from each strain and 15 larvae per vial were kept at $20^{\circ} \mathrm{C}$ with culture medium (16\% yeast, $2 \%$ sugar and $2.5 \%$ agar) until all adults had emerged.

The patterns of abdominal spots were analysed in only 10 strains for each karyotype, since the second chromosome of the remaining strains carried at least one lethal gene, which made it impossible to examine individuals autozygous for this chromosome. All strains carrying $P A O$ in the proximal region were $D A$ in the distal region of the chromosome, whereas strains carrying $P C 0$ carried $D V, D S$ or $D P$ in the distal region.

The statistical analysis was carried out using an ANOVA of the means of the number of spots per individual for each sex of each strain, to allow assessment of the effects of the second chromosome karyotype, sex and the interaction between these two factors. The advantage of using the means of each strain instead of the number of spots for each individual is that, as sample size increases, the means approach the normal distribution (Sokal and Rohlf, 1995).

\section{Crosses between strains with the same genetic background}

Since autozygosis for an entire chromosome is quite unlikely in nature, we planned crosses between strains with the same karyotype, so that the resulting offspring would simultaneously be homokaryotypic and allozygous (two alleles of independent origin) for the proximal inversions of the second chromosome. The crosses were chosen randomly among all possibilities, with the condition that each strain would participate in only two crosses. In this way, the number of crosses was equal to the number of strains available and we did not inflate the sample size.

Since it was not possible to make all of the crosses at once, they were made in sets of five. One of these crosses was repeated each time a new set of crosses was made, in order to confirm that there were no changes in the environmental conditions during the experiment.

Crosses were made with males from one strain and females from another strain. Reciprocal crosses were not carried out. Again, first instar larvae were collected from the offspring of each cross and placed in vials containing
$10 \mathrm{ml}$ of culture medium. These larvae were kept under four conditions: 12 or 96 larvae per vial, at $20^{\circ} \mathrm{C}$, and 12 or 96 larvae per vial, at $16.5^{\circ} \mathrm{C}$.

The effect of each of these variables (karyotype, temperature, density and sex) on the colour polymorphism was tested by ANOVA, in a manner analogous to the analysis of the strains.

\section{Results}

\section{Genetic analysis}

Effect of the sex chromosomes: There were no significant differences between the results of the reciprocal crosses between strains NA (pure 3) and ITC-29I (pure 0). Therefore, sex chromosomes had no significant effect (Table 1).

Autosomes: Genetic analysis revealed that the second chromosome was the most important chromosome in determining the colour polymorphism. Figure 2 shows that the phenotypes changed considerably, depending on the origin of the second chromosome (compare the lower and upper halves of each graph in the figure). In addition, ANOVA (Table 2) revealed significant effects of sex and the fifth chromosome; the third chromosome exerted an effect that bordered on significance $(P=0.088)$. ANOVA detected no significant effects for any of the interactions (not shown).

\section{Nonrandom association between karyotype and colour pattern}

Strains with different second chromosomes on the same genetic background: Figure 3 shows that strains in which the karyotype was $P A O$ usually had fewer spots than those in which the karyotype was PCO. The difference between the two karyotypes was significant, as was the difference between sexes. There was no significant interaction between these two factors (Table 3).

Crosses: The karyotype of the second chromosome had a significant effect on the phenotype of the colour polymorphism among the offspring of crosses between strains with the same genetic background for this chromosome (Table 4). Figure 4 shows that crosses between strains carrying $P A O$ tended to produce offspring with fewer abdominal spots than crosses between strains carrying PCO.

Table 1 Numbers of flies from each phenotype in reciprocal crosses

\begin{tabular}{llrrrrr}
\hline Cross & Sex & \multicolumn{4}{c}{ Number of spots } & Total \\
\cline { 3 - 6 } & & 0 & 1 & 2 & 3 & \\
\hline 1 & Males & 0 & 60 & 36 & 8 & 104 \\
& Females & 0 & 127 & 1 & 0 & 128 \\
& & & & & & \\
2 & Males & 0 & 42 & 31 & 3 & 76 \\
& Females & 0 & 83 & 2 & 2 & 87
\end{tabular}

Reciprocal crosses: 1 - females NA and males ITC-29I; 2 - females ITC29-I and males NA (Fisher's exact test, $P=0.15$ and 0.49 for females and males, respectively). 

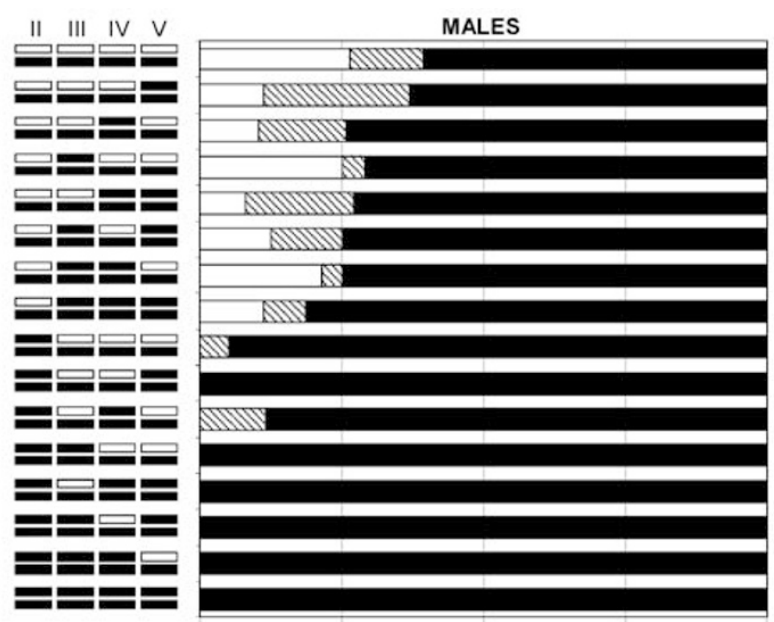

$\square$ Chromosome from ITC-29I (pure 0)

Chromosome from NA (pure 3)
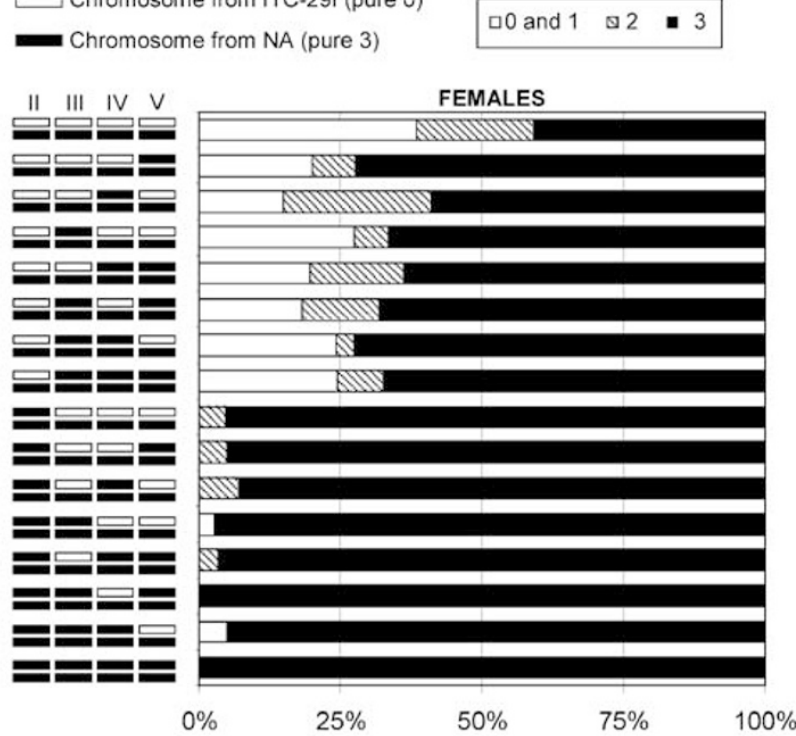

Figure 2 Percentages of the patterns of colour polymorphism based on genetic analysis showing the effects of each chromosome on males and females separately. In each chart, the effect of the second chromosome becomes evident when the upper half (where the second chromosome is a heterozygote from a pure 0 strain and a pure 3) is compared with the lower half (where the second chromosome is a homozygote from a pure 3 strain).

Table 2 ANOVA for the data used to assess the effects of each autosome and sex on the number of abdominal spots

\begin{tabular}{lrrrrr}
\hline Source & Sum of squares & df & Mean square & F-ratio & P-value \\
\hline Chromosome II & 64.440 & 1 & 64.440 & 179.932 & $<0.001$ \\
Chromosome III & 0.514 & 1 & 0.514 & 1.435 & 0.231 \\
Chromosome IV & 1.045 & 1 & 1.045 & 2.918 & 0.088 \\
Chromosome V & 2.180 & 1 & 2.180 & 6.087 & 0.014 \\
Sex & 2.184 & 1 & 2.184 & 6.099 & 0.014 \\
Error & 367.087 & 1025 & 0.358 & & \\
\hline
\end{tabular}

Other effects: Temperature had a significant effect and was the source of most of the variation (Table 4), leading to flies with more spots at lower temperatures. The effect of sex was also significant so that males tended to have more spots than females (Tables 5 and 6). In addition,
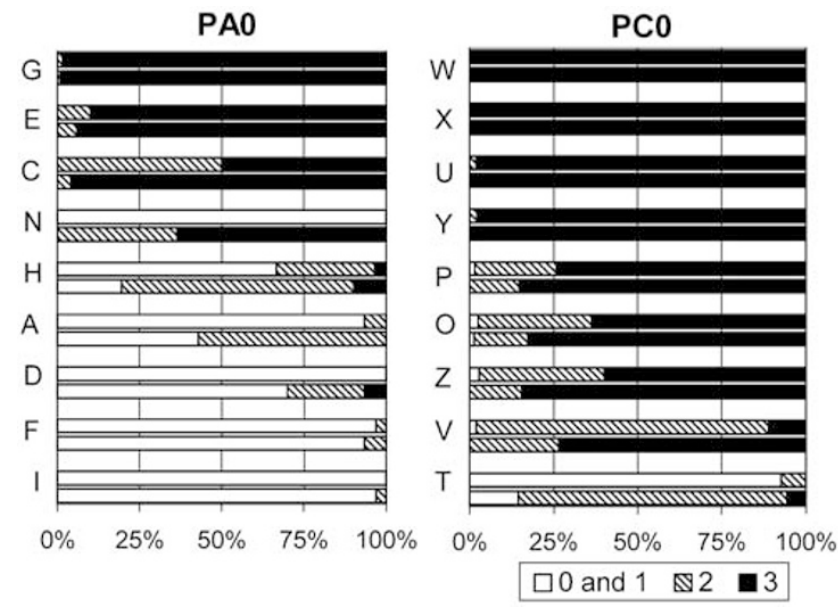

Figure 3 Percentages of the patterns of colour polymorphism in strains with different second chromosomes on the same genetic background. In each pair of bars, the upper bar indicates the proportions of the phenotypes among the females and the lower bar refers to males. Each strain is identified by a letter on the left side of the corresponding bars.

Table 3 Results of the ANOVA applied to the average number of spots per individual of each strain to assess the effects of karyotype, sex, strain (nested by karyotype) and interaction between genotype and sex

\begin{tabular}{lrrrrr}
\hline Source & Sum of squares & $d f$ & Mean square & F-ratio & P-value \\
\hline Karyotype (K) & 6.167 & 1 & 6.167 & 68.743 & $<0.001$ \\
Sex (S) & 0.938 & 1 & 0.938 & 10.458 & 0.005 \\
Strain (karyotype) & 14.546 & 16 & 0.909 & 10.135 & $<0.001$ \\
K $\times$ S & 0.064 & 1 & 0.064 & 0.710 & 0.412 \\
Error & 1.435 & 16 & 0.090 & & \\
\hline
\end{tabular}

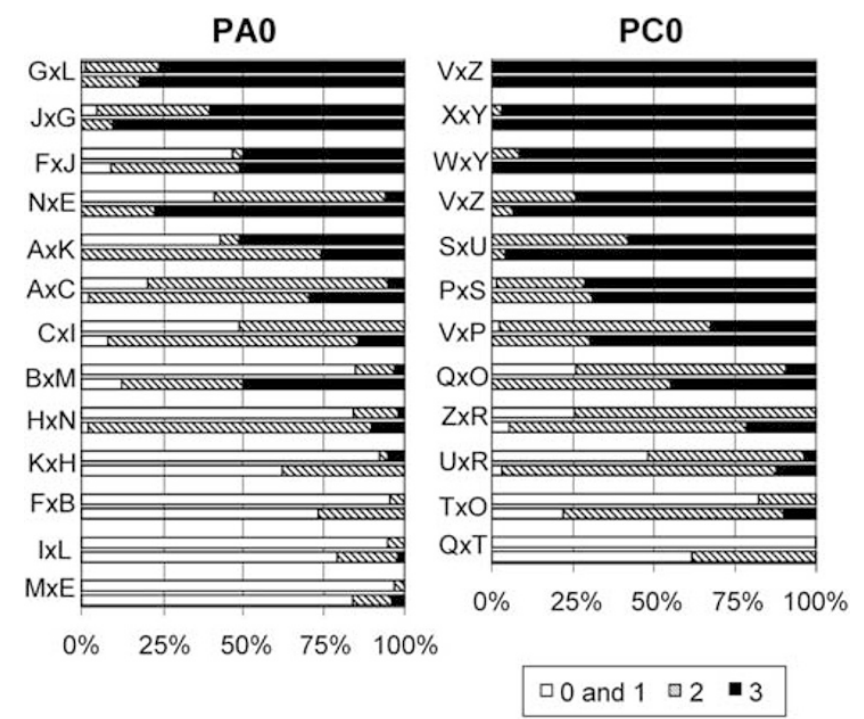

Figure 4 Patterns of colour polymorphism for crosses with different second chromosomes on the same genetic background. The data are for flies raised in $20^{\circ} \mathrm{C}$ at density of 12 larvae per vial. In each pair of bars, the upper bar indicates the proportions of the phenotypes among the females and the lower bar refers to males. The letters on the left of the bars identify each cross, corresponding to the strains in Figure 3 (for example, $\mathrm{N} \times \mathrm{E}$ is the cross between strains $\mathrm{N}$ and $\mathrm{E}$ from Figure 3). 
there were significant interactions between karyotype and temperature, and between sex and temperature, but we did not detect any significant effect of density (Table 4).

Control cross: The phenotype of the cross used as the control was particularly favourable because it was

Table 4 Results of the ANOVA applied to the average number of spots in each cross, to assess the effects of karyotype, density, temperature, sex, cross (nested by karyotype) and all possible interactions

\begin{tabular}{lrrrrr}
\hline Source & Sum of squares & $d f$ & Mean square & F-ratio & P-value \\
\hline Karyotype (K) & 6.388 & 1 & 6.388 & 53.725 & $<0.001$ \\
Density (D) & 0.026 & 1 & 0.026 & 0.215 & 0.644 \\
Temperature (T) & 34.804 & 1 & 34.804 & 292.709 & $<0.001$ \\
Sex (S) & 2.587 & 1 & 2.587 & 21.753 & $<0.001$ \\
Cross (karyotype) & 21.609 & 23 & 0.940 & 7.902 & $<0.001$ \\
K $\times$ D & 0.067 & 1 & 0.067 & 0.563 & 0.454 \\
K $\times$ T & 2.856 & 1 & 2.856 & 24.017 & $<0.001$ \\
$\mathrm{~K} \times \mathrm{S}$ & 0.031 & 1 & 0.031 & 0.257 & 0.613 \\
$\mathrm{D} \times \mathrm{T}$ & 0.018 & 1 & 0.018 & 0.148 & 0.701 \\
$\mathrm{D} \times \mathrm{S}$ & 0.001 & 1 & 0.001 & 0.008 & 0.931 \\
$\mathrm{~T} \times \mathrm{S}$ & 0.968 & 1 & 0.968 & 8.142 & 0.005 \\
$\mathrm{~K} \times \mathrm{D} \times \mathrm{T}$ & 0.010 & 1 & 0.010 & 0.085 & 0.770 \\
$\mathrm{~K} \times \mathrm{D} \times \mathrm{S}$ & 0.003 & 1 & 0.003 & 0.024 & 0.876 \\
$\mathrm{~K} \times \mathrm{T} \times \mathrm{S}$ & 0.049 & 1 & 0.049 & 0.412 & 0.522 \\
$\mathrm{D} \times \mathrm{T} \times \mathrm{S}$ & 0.002 & 1 & 0.002 & 0.017 & 0.897 \\
$\mathrm{~K} \times \mathrm{D} \times \mathrm{T} \times \mathrm{S}$ & 0.007 & 1 & 0.007 & 0.060 & 0.808 \\
Error & 18.906 & 159 & 0.119 & & \\
\hline
\end{tabular}

intermediate at $20^{\circ} \mathrm{C}$. This cross produced offspring in which neither of the extreme phenotypes (0 and 3 ) was the most common, thus allowing us to detect any displacement of the phenotype caused by environmental changes.

The use of a control cross ensured that we would detect any change in the environmental variables during the course of the experiment. This was indeed seen: significant differences between the offspring of control crosses conducted on different dates were observed (ANOVA, not shown). Thus, the crosses were reanalysed, using the logarithm of the ratios between the mean of each cross and the mean of the corresponding control cross, considering the date, sex, density and temperature. In this way, the means of the crosses were standardised to the control, in order to eliminate all environmental effects, including the influence of the factors mentioned above. This second analysis (not shown) reduced the effects of temperature and density, which became nonsignificant whereas the effect of sex remained. The interactions between karyotype and temperature, and sex and temperature also persisted and a new, marginally significant $(P=0.049)$ interaction (between density and sex) appeared.

The effect of karyotype remained highly significant and became the factor with the highest influence on the character $(\mathrm{F}=48.52 ; P=0.001)$. Thus, the mathematical correction diminished the environmental effects and emphasised the difference between the two karyotypes.

Table 5 Average number of spots per offspring in crosses between strains PA0, in relation to temperature and larval density

\begin{tabular}{|c|c|c|c|c|c|c|c|c|c|}
\hline \multirow[t]{3}{*}{ Cross } & \multirow[t]{3}{*}{ Sex } & \multicolumn{4}{|c|}{$16.5^{\circ} \mathrm{C}$} & \multicolumn{4}{|c|}{$20^{\circ} \mathrm{C}$} \\
\hline & & \multicolumn{2}{|c|}{12 larvae } & \multicolumn{2}{|c|}{96 larvae } & \multicolumn{2}{|c|}{12 larvae } & \multicolumn{2}{|c|}{96 larvae } \\
\hline & & $\mathrm{n}$ & Average & $\mathrm{n}$ & Average & $\mathrm{n}$ & Average & $\mathrm{n}$ & Average \\
\hline $\mathrm{I} \times \mathrm{L}$ & M & 22 & 3 & 11 & 3 & 48 & 1.23 & 42 & 1.17 \\
\hline $\mathrm{I} \times \mathrm{L}$ & $\mathrm{F}$ & 16 & 3 & 9 & 3 & 38 & 1.03 & 29 & 1.14 \\
\hline $\mathrm{H} \times \mathrm{N}$ & M & 24 & 3 & 29 & 3 & 49 & 2.08 & 30 & 2.00 \\
\hline $\mathrm{H} \times \mathrm{N}$ & $\mathrm{F}$ & 28 & 3 & 14 & 2.86 & 51 & 1.18 & 24 & 1.25 \\
\hline $\mathrm{F} \times \mathrm{B}$ & $\mathrm{M}$ & 10 & 3 & 13 & 2.92 & 30 & 1.27 & 5 & 1.20 \\
\hline $\mathrm{F} \times \mathrm{B}$ & $\mathrm{F}$ & 6 & 2.67 & 14 & 2.71 & 44 & 1.02 & 6 & 0.83 \\
\hline $\mathrm{C} \times \mathrm{I}$ & M & 27 & 3 & 9 & 3 & 49 & 2.06 & 29 & 1.93 \\
\hline $\mathrm{C} \times \mathrm{I}$ & $\mathrm{F}$ & 35 & 3 & 15 & 3 & 43 & 1.51 & 40 & 1.38 \\
\hline $\mathrm{J} \times \mathrm{G}$ & M & 26 & 3 & 11 & 3 & 41 & 2.90 & 21 & 3.00 \\
\hline $\mathrm{J} \times \mathrm{G}$ & $\mathrm{F}$ & 16 & 3 & 17 & 3 & 63 & 2.56 & 34 & 2.59 \\
\hline $\mathrm{A} \times \mathrm{C}$ & M & 23 & 3 & 9 & 3 & 44 & 2.27 & 18 & 2.50 \\
\hline $\mathrm{A} \times \mathrm{C}$ & $\mathrm{F}$ & 33 & 3 & 22 & 3 & 39 & 1.85 & 20 & 1.95 \\
\hline $\mathrm{K} \times \mathrm{H}$ & M & 12 & 3 & 16 & 3 & 45 & 1.38 & 31 & 1.81 \\
\hline $\mathrm{K} \times \mathrm{H}$ & $\mathrm{F}$ & 19 & 2.68 & 32 & 2.63 & 39 & 1.05 & 42 & 1.00 \\
\hline $\mathrm{M} \times \mathrm{E}$ & M & 25 & 2.64 & 25 & 2.80 & 25 & 1.20 & 34 & 1.24 \\
\hline$M \times E$ & $\mathrm{~F}$ & 19 & 2.68 & 21 & 2.57 & 33 & 1.03 & 20 & 1.00 \\
\hline $\mathrm{N} \times \mathrm{E}$ & $\mathrm{M}$ & 30 & 3 & 4 & 2.75 & 22 & 2.77 & 10 & 2.50 \\
\hline $\mathrm{N} \times \mathrm{E}$ & $\mathrm{F}$ & 26 & 2.92 & 17 & 3 & 17 & 1.65 & 13 & 2.00 \\
\hline $\mathrm{F} \times \mathrm{J}$ & M & 28 & 2.93 & 134 & 2.76 & 88 & 2.42 & 26 & 1.69 \\
\hline $\mathrm{F} \times \mathrm{J}$ & $\mathrm{F}$ & 35 & 2.69 & 66 & 2.23 & 92 & 2.03 & 30 & 1.20 \\
\hline $\mathrm{G} \times \mathrm{L}$ & M & 30 & 3 & 90 & 3 & 50 & 2.82 & 35 & 2.91 \\
\hline $\mathrm{G} \times \mathrm{L}$ & $\mathrm{F}$ & 46 & 2.96 & 60 & 3 & 75 & 2.75 & 42 & 2.88 \\
\hline $\mathrm{B} \times \mathrm{M}$ & M & 20 & 2.30 & 62 & 2.34 & 56 & 2.38 & 18 & 2.06 \\
\hline $\mathrm{B} \times \mathrm{M}$ & $\mathrm{F}$ & 31 & 2.58 & 70 & 2.34 & 33 & 1.18 & 38 & 1.74 \\
\hline $\mathrm{A} \times \mathrm{K}$ & M & 25 & 2.72 & 40 & 2.68 & 31 & 2.26 & 41 & 1.88 \\
\hline $\mathrm{A} \times \mathrm{K}$ & $\mathrm{F}$ & 26 & 2.73 & 62 & 2.52 & 86 & 2.08 & 46 & 1.07 \\
\hline Males Total & & 302 & $2.89 \pm 0.06$ & 453 & $2.87 \pm 0.06$ & 578 & $2.08 \pm 0.17$ & 340 & $1.99 \pm 0.17$ \\
\hline Females Total & & 336 & $2.84 \pm 0.05$ & 419 & $2.76 \pm 0.08$ & 653 & $1.61 \pm 0.17$ & 384 & $1.54 \pm 0.18$ \\
\hline
\end{tabular}


Table 6 Average number of spots offspring for crosses between strains PC0, in relation to temperature and larval density

\begin{tabular}{|c|c|c|c|c|c|c|c|c|c|}
\hline \multirow[t]{3}{*}{ Cross } & \multirow[t]{3}{*}{ Sex } & \multicolumn{4}{|c|}{$16.5^{\circ} \mathrm{C}$} & \multicolumn{4}{|c|}{$20^{\circ} \mathrm{C}$} \\
\hline & & \multicolumn{2}{|c|}{12 larvae } & \multicolumn{2}{|c|}{96 larvae } & \multicolumn{2}{|c|}{12 larvae } & \multicolumn{2}{|c|}{96 larvae } \\
\hline & & $\mathrm{n}$ & Average & $\mathrm{n}$ & Average & $\mathrm{n}$ & Average & $\mathrm{n}$ & Average \\
\hline $\mathrm{W} \times \mathrm{Y}$ & $\mathrm{M}$ & 36 & 3 & 45 & 3 & 53 & 3 & 47 & 3 \\
\hline $\mathrm{W} \times \mathrm{Y}$ & $\mathrm{F}$ & 33 & 3 & 56 & 3 & 60 & 2.92 & 43 & 2.91 \\
\hline$X \times Y$ & $\mathrm{M}$ & 16 & 3 & - & - & 18 & 3 & 21 & 2.86 \\
\hline$X \times Y$ & $\mathrm{~F}$ & 23 & 3 & - & - & 32 & 2.97 & 39 & 3 \\
\hline$W \times X$ & $\mathrm{M}$ & 35 & 3 & 30 & 3 & 61 & 3 & 38 & 3 \\
\hline$W \times X$ & $\mathrm{~F}$ & 27 & 3 & 38 & 3 & 77 & 3 & 50 & 3 \\
\hline $\mathrm{Q} \times \mathrm{T}$ & $\mathrm{M}$ & 28 & 2.93 & 32 & 2.90 & 47 & 1.38 & 35 & 1.46 \\
\hline$\widehat{\mathrm{Q}} \times \mathrm{T}$ & $\mathrm{F}$ & 34 & 2.36 & 30 & 2.53 & 46 & 1 & 29 & 1.03 \\
\hline$\hat{\mathrm{P}} \times \mathrm{S}$ & $\mathrm{M}$ & 30 & 3 & 25 & 3 & 84 & 2.69 & 29 & 2.69 \\
\hline$P \times S$ & $\mathrm{~F}$ & 28 & 3 & 51 & 3 & 73 & 2.70 & 30 & 2.13 \\
\hline $\mathrm{S} \times \mathrm{U}$ & $\mathrm{M}$ & 25 & 3 & 26 & 3 & 48 & 2.96 & 35 & 2.94 \\
\hline $\mathrm{S} \times \mathrm{U}$ & $\mathrm{F}$ & 38 & 3 & 25 & 3 & 50 & 2.58 & 39 & 2.44 \\
\hline $\mathrm{T} \times \mathrm{O}$ & $\mathrm{M}$ & 53 & 2.89 & 15 & 3 & 50 & 1.88 & 37 & 2.05 \\
\hline $\mathrm{T} \times \mathrm{O}$ & $\mathrm{F}$ & 46 & 2.59 & 15 & 2.73 & 51 & 1.17 & 42 & 1.33 \\
\hline $\mathrm{V} \times \mathrm{P}$ & $\mathrm{M}$ & 36 & 3 & 34 & 3 & 33 & 2.70 & 35 & 2.20 \\
\hline $\mathrm{V} \times \mathrm{P}$ & $\mathrm{F}$ & 39 & 3 & 45 & 3 & 43 & 2.30 & 35 & 2.09 \\
\hline $\mathrm{U} \times \mathrm{R}$ & M & 39 & 3 & 28 & 3 & 33 & 2.09 & 44 & 2.11 \\
\hline $\mathrm{U} \times \mathrm{R}$ & $\mathrm{F}$ & 42 & 2.98 & 56 & 2.95 & 54 & 1.56 & 46 & 1.28 \\
\hline $\mathrm{Z} \times \mathrm{R}$ & M & 59 & 3 & 28 & 3 & 56 & 2.16 & 32 & 2.19 \\
\hline $\mathrm{Z} \times \mathrm{R}$ & $\mathrm{F}$ & 61 & 2.75 & 34 & 2.79 & 51 & 1.75 & 22 & 2 \\
\hline $\mathrm{Q} \times \mathrm{O}$ & M & 50 & 3 & 26 & 2.92 & 58 & 2.45 & 26 & 2.54 \\
\hline $\mathrm{Q} \times \mathrm{O}$ & $\mathrm{F}$ & 64 & 2.89 & 31 & 2.87 & 54 & 1.83 & 31 & 2.13 \\
\hline $\mathrm{V} \times \mathrm{Z}$ & $\mathrm{M}$ & 39 & 3 & 28 & 3 & 62 & 2.94 & 43 & 3 \\
\hline $\mathrm{V} \times \mathrm{Z}$ & $\mathrm{F}$ & 46 & 3 & 40 & 3 & 66 & 2.74 & 38 & 2.92 \\
\hline Males Total & & 446 & $2.98 \pm 0.01$ & 317 & $2.98 \pm 0.01$ & 603 & $2.52 \pm 0.15$ & 422 & $2.50 \pm 0.14$ \\
\hline Females Total & & 481 & $2.88 \pm 0.06$ & 421 & $2.90 \pm 0.04$ & 657 & $2.21 \pm 0.21$ & 444 & $2.19 \pm 0.20$ \\
\hline
\end{tabular}

\section{Discussion}

\section{Genetic analysis}

Chromosomal analysis is useful for identifying the sources of genetic variation in a character among chromosomes. This classic approach has been used in the genetic analysis of hybrid sterility between $D$. pseudoobscura and D. persimilis by Dobzhansky (1936). He concluded that the inheritance of the character was polygenic, with at least one locus on each chromosome. An almost identical genetic analysis to the one used here revealed the existence of several autosomal suppressors of sex ratio in D. mediopunctata, with at least one locus in each major autosome (Carvalho and Klaczko, 1993).

Several studies have investigated the genetics of differences in abdominal pigmentation between closely related species. Spicer (1991) - applying the same experimental design used here - showed that four autosomes and the sex chromosomes had significant effects on the abdominal colour differences between $D$. virilis and $D$. novamexicana, showing that at least five loci are involved. Hollocher et al (2000) studied two species of the $D$. dunni subgroup and analysed three areas of the abdomen individually. They showed that the species differences were due to both $X$ chromosomes and autosomes, as well as maternal and paternal effects, depending on the abdominal area. Another genetic analysis between two closely related species $-D$. yakuba and D. santomea - revealed that at least three genes (each located on a different chromosome) in females and five genes in males affected the pigmentation differences between the two species (Llopart et al, 2002b). In addition, the $X$ chromosome was responsible for nearly $90 \%$ of the pigmentation differences. The difference between $D$. americana and $D$. novamexicana is also determined by at least one locus in the $X$ chromosome and a moderate number of genes located in the autosomes (Wittkopp et al, 2003).

Colour polymorphisms have also been analysed in other groups, such as the butterfly Bicyclus anynana that has been extensively studied (for a review see Brakefield, 2003). This butterfly presents seasonal variation with respect to wing colour pattern (Brakefield and Reitsma, 1991). A genetic analysis of this trait concluded that at least five genes are involved in its determination (Wijngaarden and Brakefield, 2000).

As shown here, the colour polymorphism in $D$. mediopunctata was determined by genes localised on the second and fifth chromosomes. The influence of the second chromosome was much higher than for any of the other chromosomes, suggesting the existence of a major locus or several minor effect loci on this chromosome.

Even though the $X$ chromosome seems to play an important role in the determination of the abdominal pigmentation differences between the studied species of Drosophila, we did not detect its influence on the colour polymorphism in D. mediopunctata.

Caveat: It is important to bear in mind that the genetic analysis we carried out can only detect differences between the strains analysed. Thus, there is the possibility that loci (located in other chromosomes), 
which contribute to the determination of this character, were not detected because the strains used in our experiments carried the same alleles (or alleles for equivalent effects). To minimise this limitation, we used strains selected for the maximum difference between them.

\section{Temperature, sex and density}

The effect of temperature was very intense since it increased the number of spots at the lower temperature and was responsible for most of the variation in the results of crosses between strains with the same background. In D. melanogaster and D. simulans, Gibert et al (1996) also found a strong temperature effect on abdominal pigmentation, similar to that which we observed in D. mediopunctata. In D. melanogaster and D. simulans, the influence of temperature was similar on the trident pigmentation on the thorax (Capy et al, 1988). In $D$. simulans, the trident is evident only in flies raised at low temperatures. Although there is little phenotypic plasticity for pigmentation in D. kikkawai, a more intense pigmentation is seen in flies raised at lower temperatures (Gibert et al, 1999). Increased pigmentation as a result of lower developmental temperatures is often interpreted as an adaptation for thermoregulation (Capy et al, 1988; Gibert et al, 1996, 1999): darker flies absorb more radiation and heat faster, which is advantageous in a cold environment. However, according to Stevenson (1985), any radiant heat that is absorbed by an insect as small as a Drosophila will quickly be lost by convection. Based on this, Crill et al (1996) suggested a number of alternative explanations, including nonadaptive linkage with other genes that are adaptive at low temperature, strengthening of melanised cuticles that would help compensate for larger body size, increased protection against UV radiation and concealment from visual predators when the insect tries to raise its temperature by sitting on a dark object. Therefore, the association between developmental temperature and pigmentation in Drosophila needs further investigation.

The effect of sex was always significant with males tending to have more spots than females. These results are in agreement with those of Frota-Pessoa (1954), who observed that $D$. mediopunctata males usually had more spots, which also tended to be darker than in females. A significant interaction between sex and temperature was observed, suggesting that males and females have different reaction norms. Kopp et al (2000) showed that differences in the regulation of the bric-a-brac (bab) gene are responsible for the sexual dimorphism in the abdominal pigmentation of $D$. melanogaster. They also found that males discriminate against mutant females with a male pigmentation pattern - darker abdomen but females do not show any preference between normal or mutant (ie with a female abdominal pigmentation) males, which led the authors to suggest that the less pigmented abdomen in females may be maintained by sexual selection. However Llopart et al (2002a) argued that this mechanism is unlikely to work under natural conditions (see also Stern, 2000).

Density was not an important factor determining the colour polymorphism. Freire-Maia (1964) suggested that the frequencies of the abdominal colouration phenotypes in D. kikkawai depend upon the conditions of the culture medium and larval density. This does not seem to be the case with $D$. mediopunctata.

\section{Chromosome inversions}

Since the second chromosome, which is the most polymorphic in D. mediopunctata (Peixoto and Klaczko, 1991; Ananina et al, 2002), showed greater influence on the character, we examined the correlations between inversions and the number of abdominal spots, that is, whether different second chromosome karyotypes had different effects on the colour polymorphism phenotype.

Dobzhansky (1970) believed that the suppression of recombination caused by chromosome inversions would be advantageous if the inverted region carried a supergene, such that inversions that kept coadapted gene complexes together would be favoured by natural selection. Evidence for polymorphism conditioned by supergenes has been found in land snails (Murray and Clarke, 1976; Jones et al, 1977), ladybird Adalia bipunctata (Marples et al, 1993) and butterflies (Mallet et al, 1990; Gordon and Smith, 1998).

Since chromosome inversions can behave exactly like supergenes, as predicted by Ford (1964), the existence of polymorphisms would be expected to be determined by different chromosome inversions. Several studies have demonstrated the influence of Drosophila chromosome inversions on morphological characters such as wing size and shape in D. mediopunctata (Bitner-Mathé et al, 1995), extra bristles in D. melanogaster (Izquierdo et al, 1991), size-related traits in D. buzzati (Bertrán et al, 1998) and more recently in traits showing clinal variation (Weeks et al, 2002; Calboli et al, 2003). Our results show that the colour polymorphism in D. mediopunctata is associated with chromosome inversions. Karyotype PAO was associated with phenotypes with fewer abdominal spots, whereas $P C 0$ was associated with phenotypes with more spots.

Owing to the strong linkage disequilibrium between proximal and distal inversions on the second chromosome, $P A 0$ was mainly linked to $D A$, whereas $P C 0$ was mainly linked to $D P, D V$ and $D S$ (Peixoto and Klaczko, 1991). Owing to this, the strains analysed in this work were $D A-P A O, D V-P C 0, D S-P C 0$ and $D P-P C 0$. Hence, it is possible that genes determining the colour polymorphism are also located in the distal region of this chromosome, and that the conclusions drawn here can be extended to the inversions in the distal region.

There was a significant interaction between karyotype and temperature, suggesting that the gene complexes within each karyotype had different reaction norms related to temperature.

Our results agree with two other data sets already found for this species. First, inversion frequencies in $D$. mediopunctata change during the year so that $P A O$ tends to be more frequent in colder months than in warmer months, whereas PCO undergoes the opposite changes (Klaczko, 1995). These data suggest that PAO is more adapted to lower temperatures and PCO to higher temperatures. Second, we have circumstantial evidence (unpublished data) that, in natural populations, light genotypes increase in frequency with low temperatures, while dark genotypes decrease - although, due to plasticity, the average number of spots increases, that is, flies are phenotypically darker. Since $P A O$ determines 
phenotypes with fewer spots and this karyotype increases in frequency in colder months, an increase in the frequency of genotypes leading to phenotypes with fewer spots is also expected in colder months. Thus, a comprehensive picture - even if speculative - emerges for the patterns of variation in the inversions and the colour polymorphism. Since $P A O$ seems to be adapted to lower temperatures, and PCO seems to be favoured by higher temperatures, it is possible that these inversions have undergone the accumulation of genes adapted for each of these temperature conditions. So, if the genes that determine abdominal colour patterns are located in these inversions, natural selection would favour an association in which the linked alleles would be more adapted to the temperatures in which each karyotype is the more frequent. That is, our results go exactly in the direction of the predictions of Ford (1964) that one should find an association of factors or genes determining a polymorphism forming a supergene, and that these genes would be kept together through a chromosome inversion, which would be the most efficient way to do it. This interpretation, however, remains speculative until further research confirms that the genes controlling the polymorphism are really within the inversions and that more than one gene is actually involved, hence representing a supergene. In addition, it is also necessary to investigate the adaptive significance of this colour polymorphism and whether it is under some type of balancing selection, thus helping to maintain the inversion polymorphism.

Moreover, it is necessary to study in more detail the finding of increased frequency of light genotypes with low temperatures in nature. This situation is the opposite of what is found for other species of Drosophila, which is commonly explained as an adaptive character related to the thermoregulation (the thermal budget hypothesis). For example, latitudinal clines in which genetically darker flies are found in higher latitudes were observed in the abdominal pigmentation of D. melanogaster (Das et al, 1994) and for the trident colouration of both $D$. melanogaster and D. simulans (Capy et al, 1988). Apparently, the variation in abdominal pigmentation in $D$. mediopunctata in nature can not be explained by the thermal budget hypothesis. This would lend some support for the ideas of Crill et al (1996). It opens the possibility of a number of alternative explanations, including linkage disequilibrium, which needs further investigation to be adequately tested.

We are presently working to answer these questions. Nevertheless, this is the first time an association between a conspicuous morphological polymorphism and chromosome inversions has been described.

\section{Acknowledgements}

It is a pleasure to thank L Santana for technical help and $S$ Hyslop for correcting the English version. J David and B Moreteau gave insightful suggestions. This work was supported by grants from: Conselho Nacional de Desenvolvimento Científico e Tecnológico (CNPq); Coordenação de Aperfeiçoamento de Pessoal de Ensino Superior (CAPES); Fundação de Amparo à Pesquisa de São Paulo (FAPESP); Fundo de Apoio ao Ensino e Pesquisa (FAEP-UNICAMP).

\section{References}

Ananina G, Peixoto AA, Souza WN, Klaczko LB (2002). Polytene chromosome map and inversion polymorphism in Drosophila mediopunctata. Mem Inst Oswaldo Cruz, Rio de Janeiro 97: 691-694.

Bertrán E, Santos M, Ruiz A (1998). Antagonistic pleiotropic effect of second-chromosome inversions on body size and early life-history traits in Drosophila buzzatii. Evolution 52: 144-154.

Bitner-Mathé BC, Peixoto AA, Klaczko LB (1995). Morphological variation in a natural population of Drosophila mediopunctata: altitudinal cline, temporal changes and influence of chromosome inversions. Heredity 75: 54-61.

Brakefield PM (2003). The power of evo-devo to explore evolutionary constraints: experiments with butterfly eyespots. Zoology 106: 283-290.

Brakefield PM, Reitsma N (1991). Phenotypic plasticity, seasonal climate and the population biology of Bicyclus butterflies (Satyridae) in Malawi. Ecol. Entomol. 16: 291-303.

Calboli FCF, Kennington WJ, Partridge L (2003). QTL mapping reveals a striking coincidence in the positions of genomic regions associated with adaptive variation in body size in parallel clines of Drosophila melanogaster on different continents. Evolution 57: 2653-2658.

Capy P, David JR, Robertson A (1988). Thoracic trident pigmentation in natural populations of Drosophila simulans: a comparison with D. melanogaster. Heredity 61: 263-268.

Carvalho AB, Klaczko LB (1993). Autosomal suppressors of sexratio in Drosophila mediopunctata. Heredity 71: 546-551.

Crill WD, Huey RB, Gilchrist GW (1996). Within- and betweengeneration effects of temperature on the morphology and physiology of Drosophila melanogaster. Evolution 50: 12051218.

da Cunha AB (1949). Genetic analysis of the polymorphism of color pattern in Drosophila polymorpha. Evolution 3: 239-251.

Dahlgaard J, Hasson E, Loeschcke V (2001). Behavioral differentiation in oviposition activity in Drosophila buzzatii from highland and lowland populations in Argentina: plasticity or thermal adaptation? Evolution 55: 738-747.

Das A, Mohanty S, Parida BB (1994). Inversion polymorphism and extra bristles in Indian populations of Drosophila ananassae: joint variation. Heredity 73: 405-409.

Dobzhansky T (1936). Studies on hybrid sterility. II. Localization of sterility factors in D. pseudoobscura hybrids. Genetics 21: 113-135.

Dobzhansky T (1970). Genetics of the Evolutionary Process, Columbia University Press: New York.

Ford EB (1964). Ecological Genetics, Chapman \& Hall: London.

Freire-Maia N (1964). Segregational load in Drosophila kikkawai I. Crossing experiments. Genetics 50: 211-219.

Frota-Pessoa O (1954). Revision of the tripunctata group of Drosophila with description of fifteen new species (Drosophilidae, Diptera). Arq Mus Para 10: 253-304.

Gibert P, Moreteau B, Moreteau J, David JR (1996). Growth temperature and adult convergence of reaction norms in sympatric populations? Evolution 50: 2346-2353.

Gibert P, Moreteau B, Munjal A, David JR (1999). Phenotypic plasticity of abdominal pigmentation in Drosophila kikkawai: multiple interactions between a major gene, sex, abdomen segment and growth temperature. Genetica 105: 165-176.

Gordon IJ, Smith DAS (1998). Body size and colour-pattern genetics in the polymorphic mimetic butterfly Hypolomnas misippus (L.). Heredity 80: 62-69.

Heed WB, Blake PR (1963). A new color allele at the $e$ locus of Drosophila polymorpha from northern South America. Genetics 48: 217-234.

Hollocher H, Hatcher JL, Dyreson EG (2000). Genetic and developmental analysis of abdominal pigmentation differences across species in the Drosophila dunni subgroup. Evolution 54: 2057-2071. 
Izquierdo JI, García-Vázquez E, Villar B (1991). Correlated variation of chromosomal inversion (3R)C and extra bristles in Drosophila melanogaster. Heredity 67: 183-187.

Jones JS, Leith BH, Rawlings P (1977). Polymorphism in Cepaea: a problem with too many solutions? Annu Rev Ecol Syst 8: 109-143.

Klaczko LB (1995). Population genetics of Drosophila mediopunctata. In: Levine L (ed) Genetics of Natural Populations: The Continuing Importance of Theodosius Dobzhansky, Columbia University Press: New York. pp 140-153.

Kopp A, Duncan I, Carroll SB (2000). Genetic control and evolution of sexually dimorphic characters in Drosophila. Nature 408: 553-559.

Llopart A, Elwyn S, Coyne JA (2002a). Pigmentation and mate choice in Drosophila. Nature 419: 360.

Llopart A, Elwyn S, Lachaise D, Coyne JA (2002b). Genetics of a difference in pigmentation between Drosophila yakuba and Drosophila santomea. Evolution 56: 2262-2277.

Mallet J, Barton N, Lamas G, Santisteban C, Muedas M, Eeley H (1990). Estimates of selection and gene flow from measures of cline width and linkage disequilibrium in Heliconius hybrid zones. Genetics 124: 921-986.

Marples NM, DeJong PW, Ottenheim MM, Verhoog MD, Brakefield PM (1993). The inheritance of a wingless character in the 2-spot ladybird (Adalia bipunctata). Entomol Exp Appl 69: 69-73.

Martinez MN, Cordeiro AR (1970). Modifiers of color pattern genes in Drosophila polymorpha. Genetics 4: 573-587.

Murray J, Clarke B (1976). Supergenes in polymorphic land snails. I. Partula taeniata. Heredity 37: 271-282.

Noor MAF, Grams KL, Bertucci LA, Reiland J (2001). Chromosomal inversions and the reproductive isolation of species. Proc Natl Acad Sci USA 98: 12084-12088.

Peixoto AA, Klaczko LB (1991). Linkage disequilibrium analysis of chromosomal inversion polymorphisms of Drosophila. Genetics 129: 773-777.

Pipkin SB (1962). Mesonotal color polymorphism in Drosophila l lebanonensis. Genetics 47: 1275-1290.
Powell JR (1997). Progress and Prospects in Evolutionary Biology. The Drosophila Model, Oxford University Press: New York.

Rieseberg LH (2001). Chromosomal rearrangements and speciation. Trends Ecol Evol 16: 351-358.

Rodríguez C, Fanara JJ, Hasson E (1999). Inversion polymorphism, longevity and body size in a natural population of Drosophila buzzatii. Evolution 53: 612-620.

Saavedra CCR, Callegari-Jacques SM, Napp M, Valente VLS (1995). A descriptive and analytical study of our neotropical drosophilid communities. J Zool Syst Evol Res 33: 62-74.

Sokal RR, Rohlf FJ (1995). Biometry: The Principles and Practice of Statistics in Biological Research, WH Freeman and Co.: New York.

Spicer GS (1991). The genetics basis of a species-specific character in the Drosophila virilis species group. Genetics 128: 331-337.

Stern D (2000). The problem of variation. Nature 408: 529-530.

Stevenson RD (1985). Body size and limits to the daily range of body temperature in terrestrial ectotherms. Am Nat 125: 102-117.

Vilela CR (1992). On the Drosophila tripunctata species group. Rev Bras Ent mol 36: 197-221.

Weeks AR, McKechnie SW, Hoffmann AA (2002). Dissecting adaptive clinal variation: markers, inversions and size/stress associations in Drosophila melanogaster from a central field population. Ecol Lett 5: 756-763.

Wijngaarden PJ, Brakefield PM (2000). The genetic basis of eyespot size in the butterfly Bicyclus anynana: an analysis of line crosses. Heredity 85: 471-479.

Wittkopp PJ, Williams BL, Selegue JE, Carroll, SB (2003). Drosophila pigmentation evolution: divergent genotypes underlying convergent phenotypes. Proc Natl Acad Sci USA 100: $1803-1813$

Wright S, Dobzhansky T (1946). Genetics of natural populations. XII. Experimental reproduction of some of the changes caused by natural selection in certain populations of Drosophila pseudoobscura. Genetics 31: 125-156. 